\title{
A case of dyschromatosis universalis hereditaria
}

\section{Nihal Yadav Basavaraj, Aneesh Samayam, Anjan Kumar Patra}

\author{
Department of Dermatology, MVJ Medical College and Research Hospital, Bangalore, India
}

Corresponding author: Dr. Nihal Yadav Basavaraj, E-mail: nihalyadav227@gmail.com

\begin{abstract}
Dyschromatosis Universalis Hereditaria (DUH) is a rare genodermatosis that is inherited both in autosomal dominant and autosomal recessive patterns and is reported mainly in Japan. It is characterized clinically with a peculiar pigmentary change, consisting of varying size hyperpigmented macules mingled with hypopigmented macules to give an overall impression of mottling. These lesions predominantly involve the limbs and trunk. We report a case of a eleven year old female child who presented with hypo and hyperpigmentary lesions over the trunk and limbs with a positive family history and involvement of palms and soles. Histopathology suggested features consistent with Dyschromatosis universalis hereditaria. The patient was started on Narrow Band UV-B phototherapy. The case is being reported in view of its rarity and the involvement of palms and soles, which is sparingly reported in the literature.
\end{abstract}

Key words: Dyschromatosis universalis hereditaria; Genodermatosis; Mottling

\section{INTRODUCTION}

Dyschromatoses are a group of disorders characterized by the presence of both hyperpigmented and hypopigmeneted macules many of which are small in size and irregular in shape. It is a spectrum of diseases which includes dyschromatosis universalis hereditaria (DUH), dyschromatosis symmetrica hereditaria (DSH) or acropigmentation of Dohi and a segmental form called unilateral dermatomal pigmentary dermatosis (UDPD) [1]. In DUH, pigmentation appears in a generalized distribution. Both autosomal dominant and autosomal recessive forms have been reported [2].

We report a case of DUH in a eleven year old female child with a positive family history and involvement of palms and soles.

\section{CASE REPORT}

A eleven year old female patient presented to our OPD with complaints of black and white patches all over the body since six months of age. She spontaneously developed these dyschromic macules initially over the elbows which then progressed over a period of five months to involve both upper and lower limbs, chest, abdomen, back and upper part of the face. The lesions were not associated with pain or itching. She had no history of photosensitivity, ocular or mental abnormalities, handling any chemical directly or any significant history of drug intake. Similar complaints was present in the family. Cutaneous examination revealed hypopigmented and hyperpigmented macules of irregular shape and size present diffusely over bilateral upper and lower limbs, chest, upper part of the face and also involving the palms and soles (Figs. 1 - 4). There was no hair, nail or mucosal involvement. Systemic examination was normal. Punch biopsy of skin from hyperpigmented macule showed marked increase in epidermal basal melanin (Fig. 5) and biopsy from hypopigmented macule showed a decrease in epidermal basal melanin (Fig. 6). Basal vacuolar change and dermal mild chronic inflammatory cell infiltrate was seen with both specimens. Features were consistent with dyschromatosis universalis hereditaria. She was started on Narrow Band UV-B phototherapy.

\section{DISCUSSION}

Dyschromatoses are a group of disorders characterized by the presence of both hyperpigmented and hypopigmented macules. It is a spectrum of diseases

\footnotetext{
How to cite this article: Basavaraj NY, Samayam A, Patra AK. A case of dyschromatosis universalis hereditaria. Our Dermatol Online. 2020;11(e):e.98.1-e.98.3. Submission: 24.09.2019; Acceptance: 09.11.2019

DOI: $10.7241 /$ ourd.2020e. 98
} 


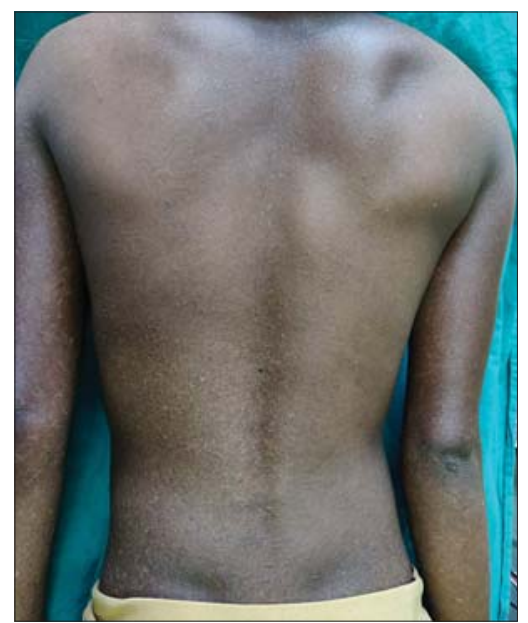

Figure 1: Hypopigmented and hyperpigmented macules in a mottled pattern over lower back and arms.

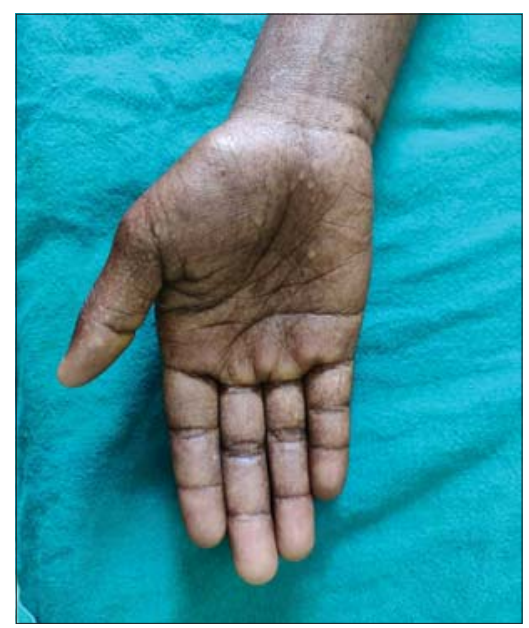

Figure 2: Hypopigmented and hyperpigmented macules in a mottled pattern over the palm.

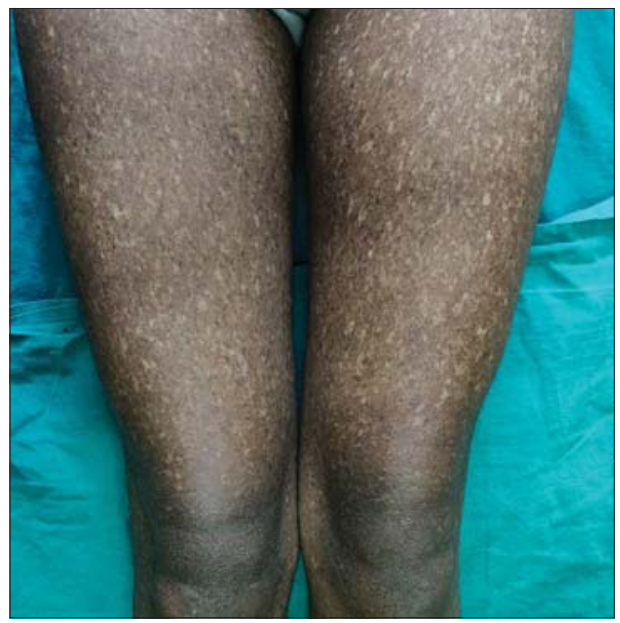

Figure 3: Hypopigmented and hyperpigmented macules in a mottled pattern over thighs.

which includes DUH, DSH and a segmental form called unilateral dermatomal pigmentary dermatosis [3].

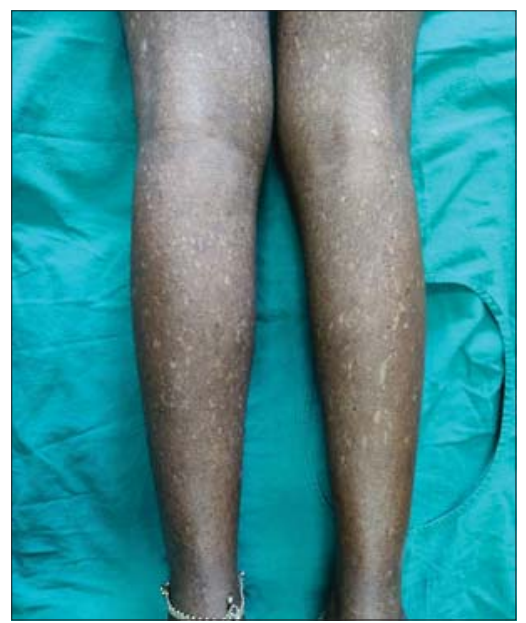

Figure 4: Hypopigmented and hyperpigmented macules in a mottled pattern over legs.

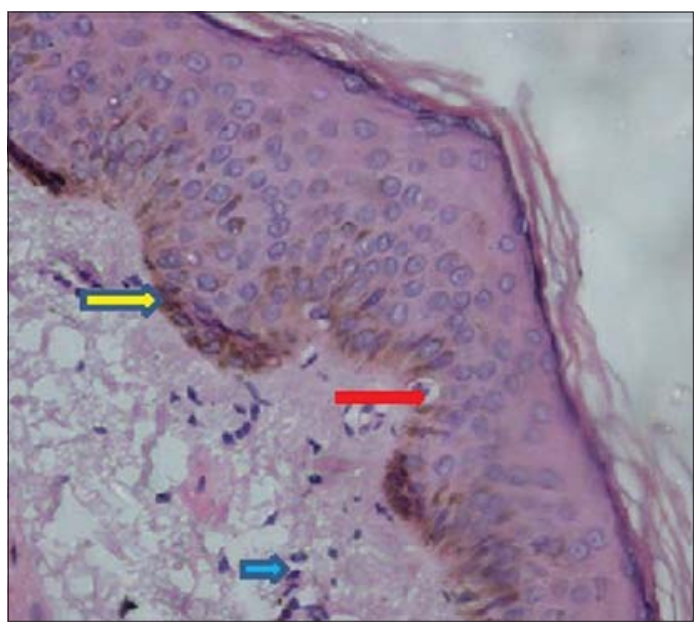

Figure 5: Punch biopsy from hyperpigmented macule showing stratified squamous epithelium with hyperkeratosis, marked pigmentation of the basal layer and basal vacuolar change. Dermis shows inflammatory cell infiltrate. Legend: yellow arrow - increased basal melanin pigmentation; red arrow - basal vacuolar change; blue arrow - inflammatory cell infiltrate.

In 1929, Toyama described DSH as a distinct entity, later in 1933, Ichikawa and Hiraga described DUH, which had similar features of DSH but occurring in generalized as opposed to acral distribution.

The etiology of this disorder is not known. A novel mutation in RNA-specific adenosine deaminase gene (ADARl, DSRAD) was reported in DSH without identifying such mutation in DUH [4]. Recently, ABCB6 has been identified as the first pathogenic gene associated with DUH [5].

DUH manifests as generalized hypo and hyperpigmented macules in first few years of life. The trunk and extremities are the dominant sites. Facial involvement 


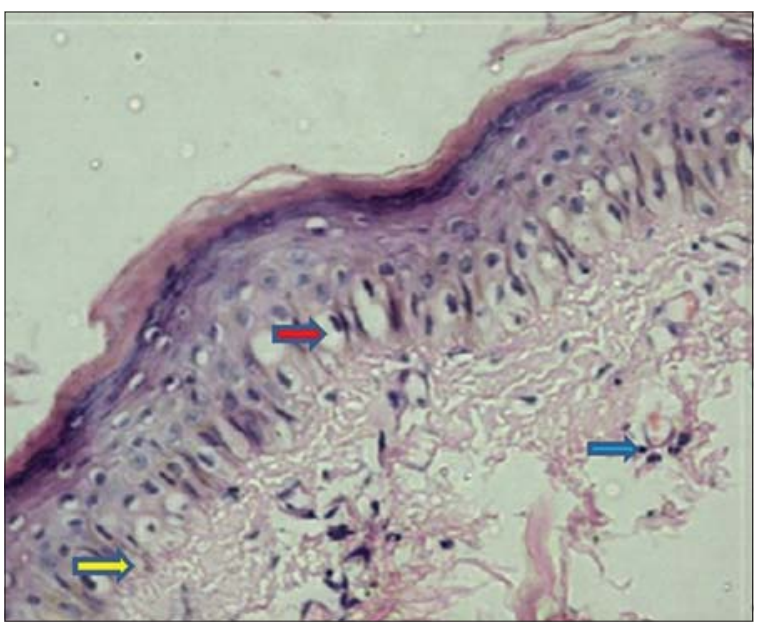

Figure 6: Punch biopsy from hypopigmented macule showing stratified squamous epithelium with hyperkeratosis, decreased pigmentation of the basal layer and basal vacuolar change. Dermis shows inflammatory cell infiltrate. Legend: yellow arrow - decreased basal melanin pigment; red arrow - basal vacuolar change; blue arrow - inflammatory cell infiltrate.

can be seen in $50 \%$ of the affected individuals, but involvement of palms and soles is rare [6]. In our case, trunk and extremities were the predominant sites with involvement of face, palms and soles also. DUH may be associated with abnormalities of dermal connective tissue, nerve tissue or be associated with other systemic complications [1]. No such features characterized our patient.

The histopathology shows an increase or decrease in melanin content of basal layer (depending on the type of lesion biopsied) and occasional pigmentary incontinence. The features were consistent in our patient.

Lesions of DUH have to be differentiated from xeroderma pigmentosum, since in both disorders patients show lesions in the photoexposed areas. However, in DUH, lesions occur in unexposed sites as well and moreover show no atrophy or telangiectasia. Generally, DUH does not progress or worsen with age [2]. Spontaneous regression is not known.

\section{CONCLUSION}

DUH is being increasingly reported from India. Despite its rarity, DUH assumes significance as it forms an important differential diagnosis of xeroderma pigmentosum. Role of NBUVB as a treatment modality should be evaluated and tried for better cosmetic appearance.

\section{Consent}

The examination of the patient was conducted according to the Declaration of Helsinki principles.

The authors certify that they have obtained all appropriate patient consent forms. In the form the patient(s) has/have given his/her/ their consent for his/her/their images and other clinical information to be reported in the journal. The patients understand that their names and initials will not be published and due efforts will be made to conceal their identity, but anonymity cannot be guaranteed.

\section{REFERENCES}

1. Gupta M. Dyschromatosis universalis hereditaria with sensorineural hearing loss. Egypt J Dermatol Venerol. 2016;36:26-7.

2. Namitha P, Sacchidanand S. Dyschromias: A series of five interesting cases from India. Indian journal of dermatology. 2015;60:636

3. Naveen KN, Dinesh US. Dyschromatosis universalis hereditaria with involvement of palms. Indian Dermatol Online J. 2014;5:296.

4. Kumar S, Bhoyar P, Mahajan BB. A case of dyschromatosis universalis hereditaria with adermatoglyphia: A rare association. Indian Dermatol Online J. 2015;6:105-9.

5. Zhang C, Li D, Zhang J, Chen X, Huang M, Archacki S, et al. Mutations in ABCB6 cause dyschromatosis universalis hereditaria. J Invest Dermatol. 2013;133:2221-8.

6. Sirka CS, Sahu K, Rout AN. Dyschromatosis universalis hereditaria with hypospadias: A rare association. Indian Dermatol Online J. 2020;11:243-5

7. Merino de Paz N, Rodríguez-Martin M, Contreras Ferrer P, PestanaEliche M, Martin-Herrera A, Noda-Cabrera A. Photoletter to the editor: Dyschromatosis universalis hereditaria: An infrequently occurring entity in Europe. J Dermatol Case Rep. 2012;3:96-7.

Copyright by Nihal Yadav Basavaraj, et al. This is an open-access article distributed under the terms of the Creative Commons Attribution License, which permits unrestricted use, distribution, and reproduction in any medium, provided the original author and source are credited.

Source of Support: Nil, Conflict of Interest: None declared. 